\title{
MOBILE MACHINES FOR THE MACHINING OF LARGE DIMENSION PARTS
}

\author{
O. Legoff ${ }^{1}$, M. Ritou ${ }^{2 \star}$, C. Maurin ${ }^{3}$, S. Bonnet ${ }^{4}$, B. Furet ${ }^{2}$ \\ 'LS2N (Laboratory of Digital Sciences of Nantes, UMR CNRS 6004), Centrale Nantes, Nantes, France \\ ${ }^{2}$ LS2N (Laboratory of Digital Sciences of Nantes, UMR CNRS 6004), University of Nantes, Nantes, France \\ ${ }^{3}$ NAVAL Group, Indret, France \\ ${ }^{4}$ Capacités, Carquefou, France \\ *Corresponding author; e-mail: mathieu.ritou@univ-nantes.fr
}

\begin{abstract}
The machining of large dimension part presents issues of accuracy and of part handling. Machine-tools of large capacity are classically used, but they are very expensive. The paper investigates original solutions with mobile milling machines. A comparative study of a machining robot and of a portable milling machine is performed. Instrumented experiments of face milling operation were carried out and the resulting quality was analyzed. Finally, the manufacturable precision for the large part is assessed by the tolerance stacking model that is proposed.
\end{abstract}

\section{Keywords:}

Mobile machine; Robotic machining; Large dimension

\section{INTRODUCTION}

Many sectors require the manufacture of high-precision parts of large dimensions: naval, railway, nuclear, aeronautics, renewable energies, etc. Their machining is usually done on a machine-tool, which guarantees a sufficient quality. But specific difficulties appear:

- transport and handling of parts in the workshop (infrastructure limit, duration);

- the positioning and fixturing of the part, enabling accessibility to the machined features;

- investment in a machine-tool that is difficult to make profitable;

- working conditions;

- the high costs that result from the previous points.

Suitable machine-tools, at reasonable cost, exist for machining large profiles, having one large dimension (with a bar feeder); or large plates, having two large dimensions (with a router or a gantry machine). On the other hand, if the piece is large according to its three dimensions, it then presents a very large volume (for example, $12 \mathrm{~m} \times 4 \mathrm{~m} \times$ $3 \mathrm{~m}$ and a weigh of a hundred tons) and complexity is higher. Very large machine-tools, costing several million euros, are necessary. The type is often a boring machine, which consists in a movable column supporting a ram. In addition, parts with such dimensions are generally produced in small number, making the return on invest difficult.

Rather than bringing a large-scale piece into a very large machine, the alternative is to place a small dedicated machine on the large workpiece [1]. However, a mobile machine generally offers reduced functionalities due to its minimal structure, and lower precision due to lower rigidity coupled with repositioning errors. In literature, Uriate et al. [1] present a comprehensive state of the art for the machining of large parts, with the different machine structures that can be encountered. A decision-support approach is also proposed in literature, for the choice of optimal machine with regard to functional and specialization aspects [2].

Besides, in recent years, industrial articulated robots are more and more studied and used for the machining of metallic or composite parts $[3,4]$. It is known that the structure of the machine has an impact the accuracy that can be expected [5]. This is particularly true for machining robots. Their low stiffness has a significant impact on the quasi-static behavior of the process, conducting to large toolpath deviation [6,7]. Different offline or online compensation strategies are possible [8]. The low stiffness has also an impact on the robot dynamics [9]. Besides, the natural frequencies of the robot vary with the robot position and configuration [10,11], which increases the difficulty. The machining strategy [12] and the spindle dynamics $[13,14]$ can also have an impact.

This paper presents a comparative study of mobile machines for face milling operation on large-scale part. Two machines were selected: a robot and a portable milling machine. The experimental setup for the machining tests is presented. The geometrical quality of the machined surfaced was measured. These results are then put in perspective by a geometric simulation model of the manufacturable quality. 


\section{PROPOSITION OF MOBILE MACHINES FOR MACHINING}

To solve the problem of large part machining, two mobile machine solutions were considered (Figure 1). The first one is a poly-articulate robot. This solution offers a large working space, considering the space required for its installation, and a layout facilitated by the 6 degrees of freedom of its structure. The behavior of the robot, under large cutting forces for steel, is worth to be studied, due to the flexibility of its structure.

After a search for mobile machining machine, a portable milling machine, with a Cartesian structure, was selected. It has a more rigid structure, despite a more restricted work space and the need for a more sensible setup of its perpendicularity in relation to the workpiece.

The two machines present different kinematic chain and spindle technologies, but they are comparable and potentially adapted to the industrial use case. Indeed, both machines have a working space enabling face milling operation on a sample of $1 \mathrm{~m}$ long (corresponding to the geometrical features of the industrial use case). Although the arm of the robot is a bit longer, its accessibility to the workpiece is similar. Besides, this robot is rather stiff and promising, compared to other robots and particularly to smaller ones [15]. The robot can be roughly estimated as fifty times less stiff than the portable machine. The two spindles have a sufficient torque at low speed for face milling operation in steel with a $100 \mathrm{~mm}$ diameter tool. Therefore, the comparison between the two machine+spindle is relevant.

The following sections present the experimental protocol and the results obtained with these two mobile machines. For this feasibility study, focus has been done on the determination of suitable cutting conditions and on the measurement of the resulting flatness and roughness of the machined surface for each machine. The repositioning of each machine is out of the scope of the paper.

\section{EXPERIMENTAL SET-UP}

The feasibility study consists in a test campaign with the two machines whose main characteristics are:

- Machining robot: Kuka KR270 6-axis robot $(2.3 \mathrm{~m}$ range, $1270 \mathrm{~kg}$ ), equipped with a Fischer 24,000 rpm - 20kW electro-spindle with HSK63A interface.

- Portable milling machine: $X$ travel $=1524 \mathrm{~mm}, Y=$ $406 \mathrm{~mm}, Z=101 \mathrm{~mm}$, for $830 \mathrm{~kg}$, equipped with a $500 \mathrm{rpm}$ hydraulic spindle with BT40 interface and gear transmission.

The two cutting tools are:

- A face milling cutter, $D=100 \mathrm{~mm}, Z=5$ teeth, $45^{\circ}$ entering angle, square carbide inserts.

- A bullnose tool, $D=40 \mathrm{~mm}, Z=5$ teeth, $R=5 \mathrm{~mm}$ round carbide inserts.

The design of experiment is based on two steps. A first step investigates the feasibility, by searching adequate cutting conditions $\left(a_{p}, f_{z}\right)$ for each of the 2 tools, on each of the 2 machines. Then, for the most promising tool for each machine, the impact of the machining strategy (robot position and direction ...) is tested, following a OFAT method (One Factor At a Time).

For each trial cut, a face milling operation was performed on S355 steel samples of $1000 \times 200 \times 25 \mathrm{~mm}$, with dry cuts.

The parameters of the tests are:

- The two tools: D100 and D40.
- The machining strategy: 3 positions of the robotmachine, 4 feed directions and 2 cutting modes (up/downmilling), zig-zag and one-way strategies.

- The cutting conditions (depth of cut $a_{p}$, feed per tooth $\mathrm{f}_{z}$ ).

The measurements to evaluate the resulting quality of the trial cuts are:

- The in-process vibrations, with an accelerometer on the spindle housing.

- Visual inspection: some sets of cutting conditions were rejected due to too poor surface quality obtained.

- Geometrical measurements of the machined surfaces: flatness deviation $(\mathrm{Pt})$, waviness $(\mathrm{Wt})$ and roughness $(\mathrm{Ra})$ were quantified by CMM and profilometer.

Around 100 cutting tests were performed and analyzed. The main results are presented in the following section.
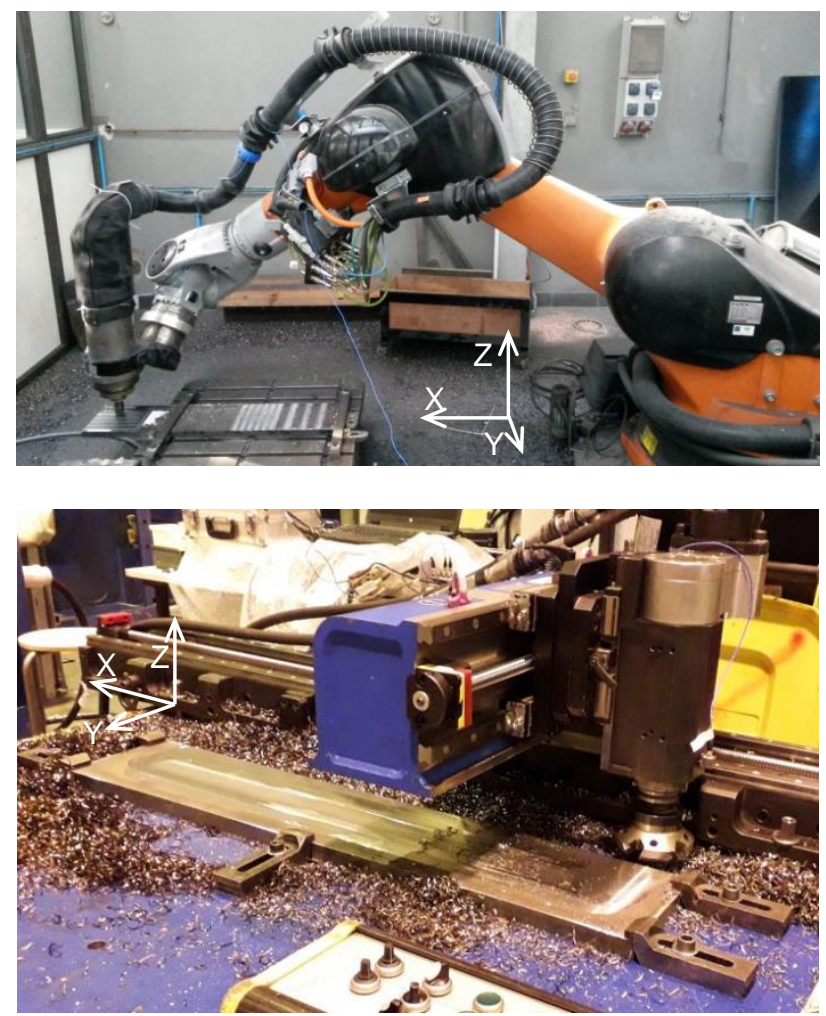

Fig. 1: Mobile machines for the cutting tests: machining robot and portable milling machine.

\section{RESULTS}

\subsection{Machining robot}

It has been possible to determine adequate sets of cutting conditions with the D40 bullnose tool, but impossible with the D100 face milling cutter. Indeed, the large of engagement of the D100 is too sensible to deflection and interaction with the robot structure. To the contrary, the D40 tool with round insert is well adapted. The following results concern the D40 tool.

Suitable cutting conditions were found with $a_{p}=0.5 \mathrm{~mm}$ $(\mathrm{N}=2400 \mathrm{rpm}, \mathrm{Vf}=1200 \mathrm{~mm} / \mathrm{min})$. It leads to acceptable surface quality $(\mathrm{Wt}=7.3 \mu \mathrm{m}$, see Table 1 and the picture in Fig. 3). In that case, the in-process vibration level is $\mathrm{V}_{\mathrm{RMS}}=6.5 \mathrm{~mm} / \mathrm{s}$ (see Fig. 3 in the time domain), which is an acceptable level. It corresponds to forced vibrations (see harmonics of the spindle rotation frequency $f_{s}=$ 
$40.6 \mathrm{~Hz}$ in the frequency spectrum Fig. 3). A few asynchronous contributions can be noticed in the corresponding frequency spectrum, without a significant impact on the waviness of the machined surface. Higher vibration levels are obtained at the entry and mainly at the exit of the tool. It leads to marks on the workpiece at the tool exit.

Besides, there are quasi-static deflections of the robot during the steady cutting zone, at a constant value due to the cutting forces. The deflections progressively increase at the tool entry and decrease at the exit. As a consequence, most of the flatness error is located in these transient cutting zones (cf. Fig 5).

These acceptable machinings were obtained for specific motions of the robot, corresponding to a pushing motion of the arm. Moreover, it was only for a restricted range of cutting conditions (cf. Tab 1). Indeed, too large depth of cut $a p$ leads to structural vibration of the robot, and too small ones to minimum chip thickness issues. Furthermore, it is difficult to remove a given programmed depth of cut $a_{p}$ from one path to another. Deviations are obtained, due to quasi-static deflections of the robot.

For other motion direction at the same robot position (with identical cutting conditions), significant cutting vibrations were obtained, leading to unacceptable surface waviness. It was particularly observed when the feed direction corresponds to a pulling motion of the robot (cf. top of Fig. 2). Cutting instability occurred at a structural eigenfrequency of the robot at $13.7 \mathrm{~Hz}$, in the vertical direction $Z$ (as can be seen, in green, on the left of the frequency spectrum in Fig. 2). Indeed, it corresponds to the natural frequency of the robot+spindle that were obtained at $13.6 \mathrm{~Hz}$ by tap-test for a close position of the robot (cf. FRF at spindle noze in $Z$ direction, Fig. 4). Moreover, modulation at $+/-1.44 \mathrm{~Hz}$ can be observed around this natural frequency and its harmonics, in Fig. 2 in-process spectrum. An hypothesis is that it might be related to the coupling (proximity) of two eigenfrequencies in the FRF. The vibration level then reaches $\mathrm{V}_{\mathrm{RMS}}=90$ $\mathrm{mm} / \mathrm{s}$, which is unacceptable.

As a consequence, zig-zag strategy is inappropriate and only one-way strategy is applicable, due to the restricted motions along a pushing direction of the robot (for a limited range of cutting conditions and with the $40 \mathrm{~mm}$ diameter tool). The resulting surface quality is relatively correct, as shown by the measurements presented in Fig. 5 and Tab. 1.
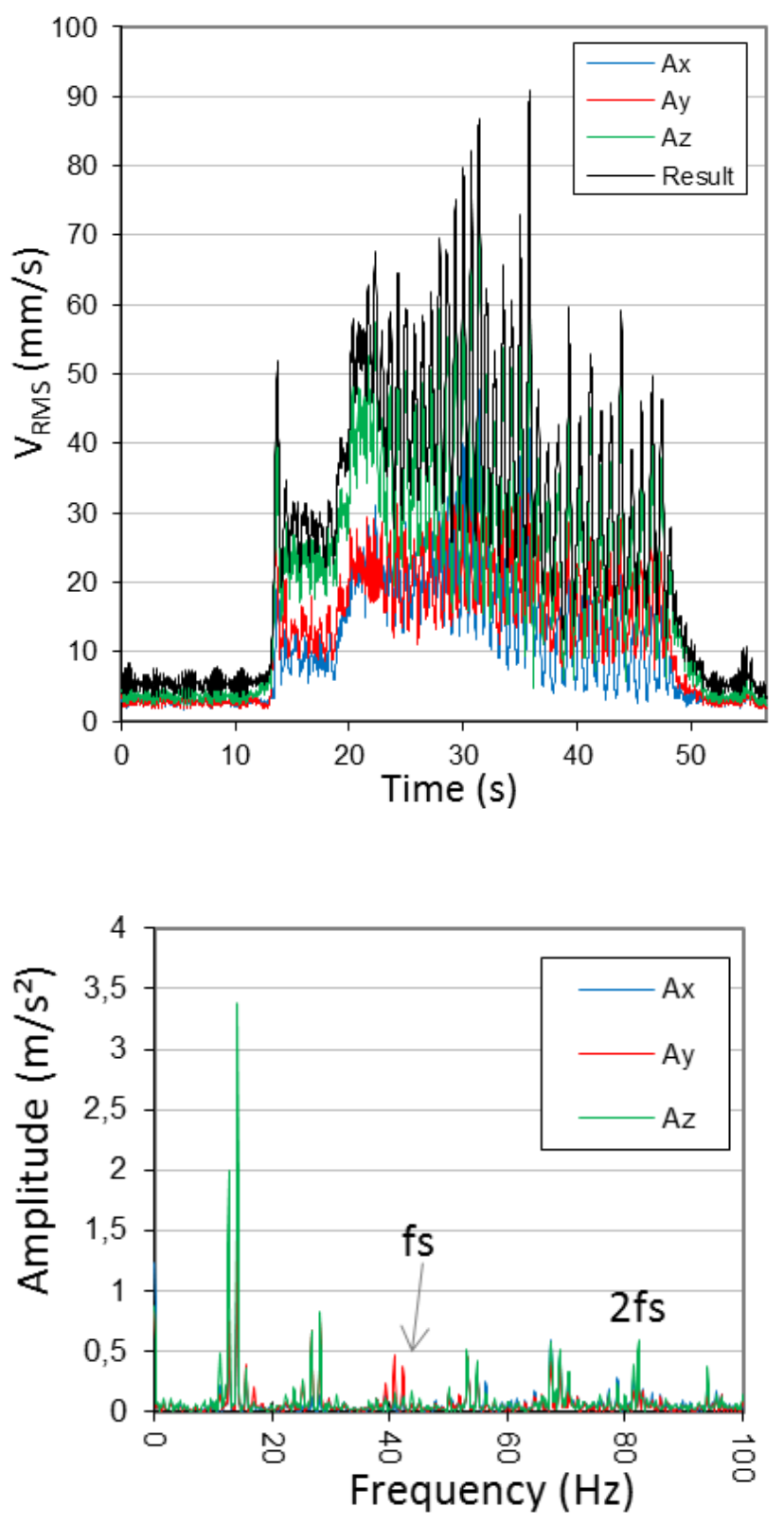

Fig. 2: Instable vibrations of robotic machining, with a pulling motion of the robot $\left(a_{p}=0.5 \mathrm{~mm}\right)$, in time and frequency domains; and the resulting surface quality.
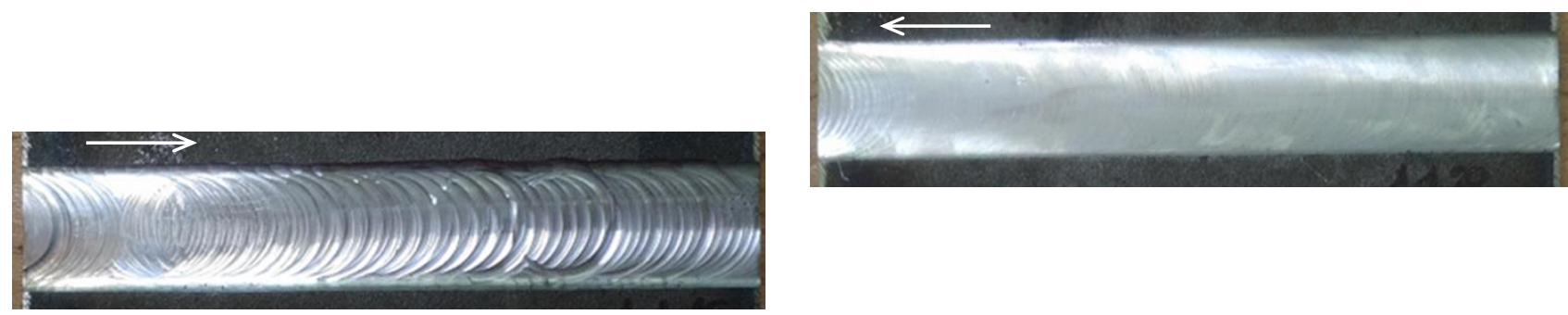

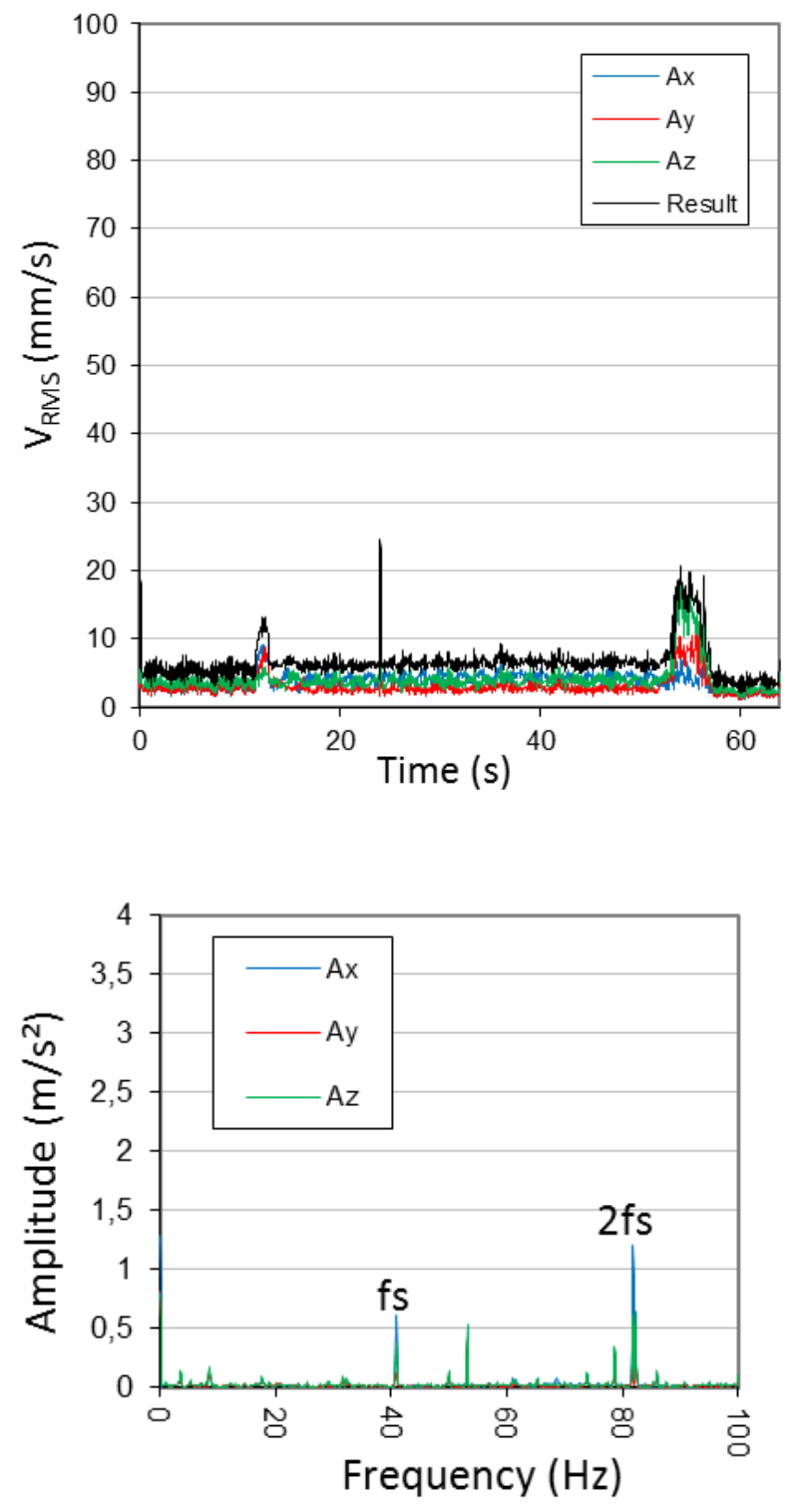

Fig. 3: Stable vibrations of robotic machining, with a pushing motion of the robot $\left(a_{p}=0.5 \mathrm{~mm}\right)$, in time and frequency domains; and the resulting surface quality.

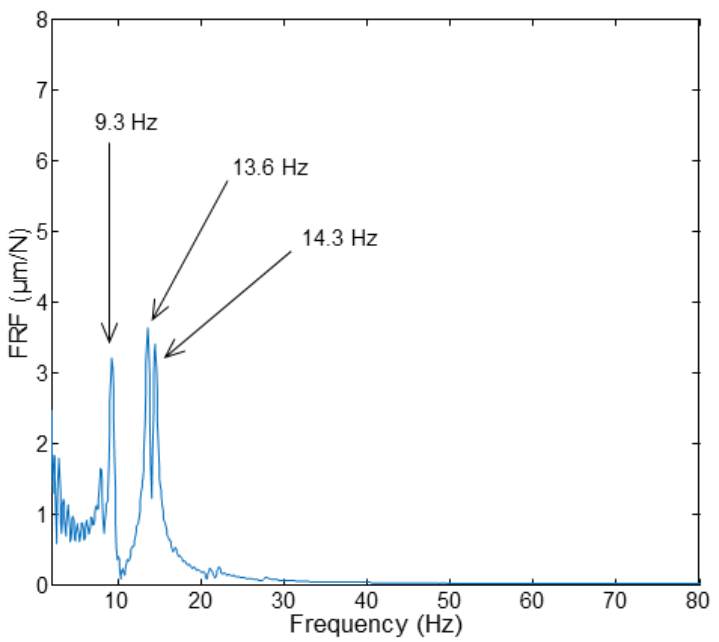

Fig. 4: Frequency Response Function (FRF, in Z direction) of the robot+spindle in the favorable robot position of Fig. 2 \& 3 cutting tests.

\subsection{Portable milling machine}

Trial cuts with the portable milling machine generally led to good surface quality on the workpiece; especially with the face milling cutter of $100 \mathrm{~mm}$ diameter. Productivity and quality were lower with the $40 \mathrm{~mm}$ diameter tool. Thus, the following results concern.

Vibration levels are moderate, with $V_{\mathrm{RMS}} 14 \mathrm{~mm} / \mathrm{s}$, for good cutting conditions with the $\mathrm{D} 100$ tool $(\mathrm{N}=300 \mathrm{rpm}$, $\mathrm{Vf}=150 \mathrm{~mm} / \mathrm{min}, \mathrm{ap}_{\mathrm{p}}=0.5 \mathrm{~mm}$ ).

It has been observed that the behavior of the hydraulic spindle varies according to the oil temperature. The spindle speed increases as the oil temperature increases, due to variation of oil viscosity. Spindle speeds above 500 rpm generate excessive vibrations, limiting the cutting speed. Besides, from depth of cut of $2 \mathrm{~mm}$, a high vibration level of $V_{\text {RMS }}=60 \mathrm{~mm} / \mathrm{s}$ leads to recommend lower $a_{p}$ of $1 \mathrm{~mm}$ (cf. Tab 1).

Both one-way and zig-zag strategies lead to interesting surface quality. Therefore, zig-zig is recommended since higher productivity is obtained.

\subsection{Comparisons}

As discussed in section 2, the two machines are potentially adapted to the industrial use case and their comparison is relevant.

Considering a favorable configuration (tool, strategy, $\mathrm{N}$ ) for each mobile machine, Table 1 summarizes the experimental results, according to three levels of surface quality $(' 0$ ' $=$ not acceptable, ' + ' = acceptable, ' ++ ' = recommended), in order to define the possible operating conditions. The coordinate systems associated to each mobile machine are defined in Figure 1.

Tab. 1: Results of cutting tests with the mobile machines.

\begin{tabular}{cccccc}
\hline $\mathrm{a}_{\mathrm{p}}[\mathrm{mm}]$ & 0.1 & 0.5 & 1 & 1.5 & 2 \\
\hline Robot & 0 & + & 0 & 0 & 0 \\
\hline Machine & ++ & ++ & ++ & + & 0 \\
\hline Direction & $\mathrm{X}+$ & $\mathrm{X}-$ & $\mathrm{Y}+$ & $\mathrm{Y}-$ & \\
\hline Robot & + & 0 & 0 & 0 & \\
\hline Machine & ++ & ++ & + & ++ & \\
\hline $\begin{array}{c}\text { Surface } \\
\text { quality }\end{array}$ & $\mathrm{Pt}$ & $\mathrm{Wt}$ & $\mathrm{Ra}$ & & \\
\hline Robot & 0.8 & {$[\mu \mathrm{m}]$} & {$[\mu \mathrm{m}]$} & & \\
\hline Machine & 0.4 & 3.3 & 1.1 & & \\
\hline
\end{tabular}

In the optimal configuration of each machine, face milling operations were carried out with both portable machine (with a one-way strategy for the robot and a zig-zag one for the potable milling machine). The resulting machined surfaces were scanned with a laser on a CMM. Results of form deviation (flatness $\mathrm{Pt}$, a first order defect) are presented in Fig. 5. and Tab. 1. The defects produced with the robot mainly concern the tool entry and exit (overcut in bleu). In addition, scallop height can be observed between adjacent paths (undercut in red). The defects obtained with the portable machine are mainly due to the workpiece fixturing and not to the machine deflection. With $0.4 \mathrm{~mm}$, it is twice smaller than the robot one. Shape defects of second order (total waviness $\mathrm{Wt}$ ) and third order (arithmetic roughness $\mathrm{Ra}$ ) were measures with a profilometer (Tab. 1). Waviness is also twice better with 
the mobile machine. In presence of such first and second order defects, the comparison of roughness does not make sense.

As a conclusion, relatively acceptable surface quality can be achieves with the poly-articulated robot, but only in some too restrictive configurations; while the portable milling machine always leads to good results, opening up more possibilities.

\section{SIMULATION OF GEOMETRICAL QUALITY}

The intrinsic precision of the machines was experimentally studied in the previous section. The extrinsic defect related to the repositioning of the mobile machines also affects the precision of the machining. However, because of their very different kinematics and workspace, same repositioning defects could have different consequence on the machined part. The combination of both intrinsic and extrinsic defects should be considered in order to assess the precision that can be obtained on a large-scale part.

Based on the models proposed by Legoff et al. [16,17], the compact graph of Figure 6 models the machining of two batches of three planes $\left\{p_{10}, p_{11}, p_{12}\right\}$ and $\left\{p_{20}, p_{21}, p_{22}\right\}$ on a part $\mathrm{P}$, corresponding to two different positions $\mathrm{M} 1$ and M2 of the mobile machine.

For face milling operations where the machined, positioning and reference surfaces are nominally parallel planes, each defect can be modelled by two angular deviations and one normal displacement. A given batch of planes, machined with a given machine position $i$, are considered as Common Zone (CZ).

The Form Deviation (FD) of a machined plane is defined as the intrinsic defect of a machine, due to the in-process deflections of the machining, identified experimentally in the previous section. Thus, the FD of the planes of a given batch should not be cumulated, they are identical. Only the relative position between planes can increase the defect.

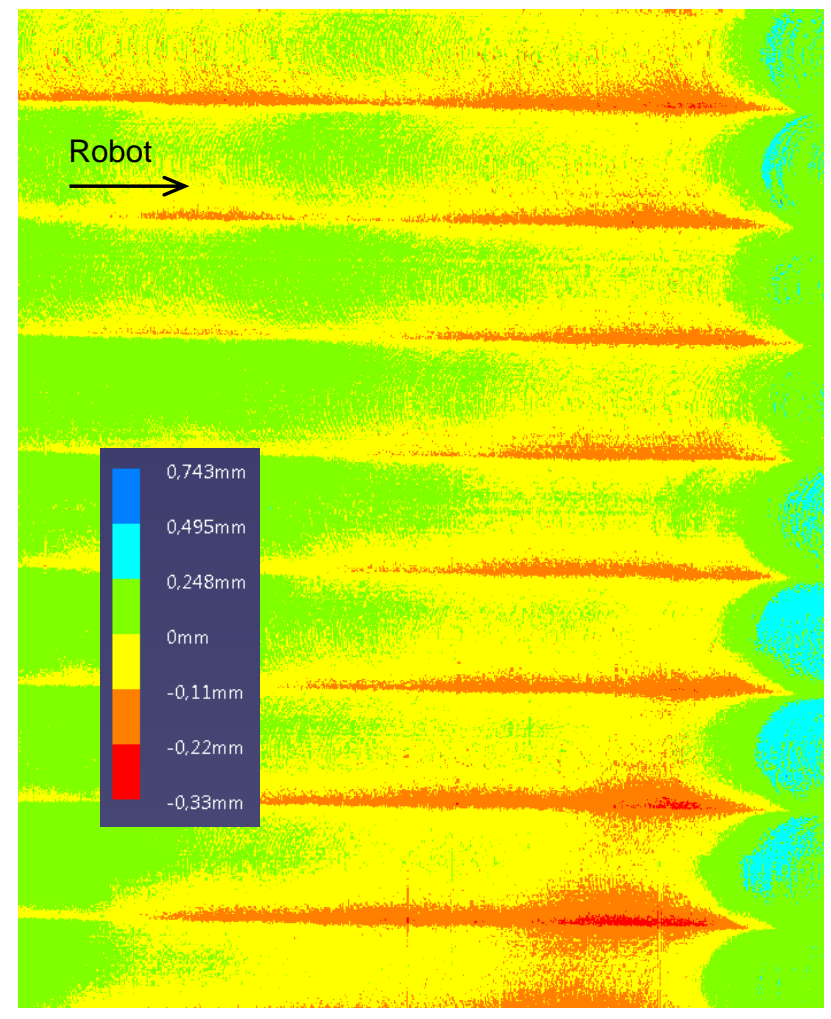

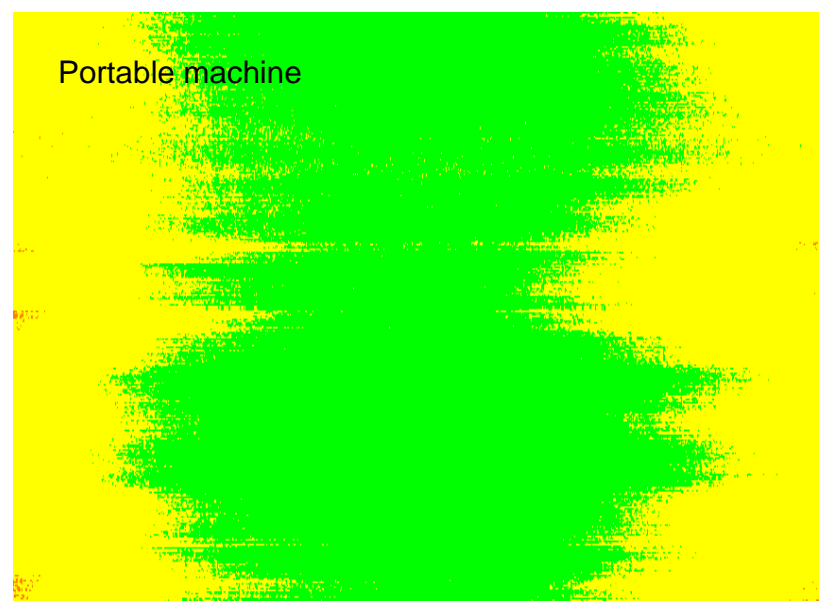

Fig. 5: Deviation of the machined surfaces with the robot (on the top) and the portable machine (on the bottom), measured by laser on a CMM.

Consequently, are modeled:

- The repositioning defect of the machine, in relation to the part reference frame: $\Delta \mathrm{P}, \mathrm{M}_{\mathrm{i}}$.

- The machine setting faults (calibration, probing): $\Delta \mathrm{M}_{\mathrm{i}}, \mathrm{p}_{\mathrm{j}}$.

- Form deviation FD of the machined surface (due to the in-process deflections of the machining).

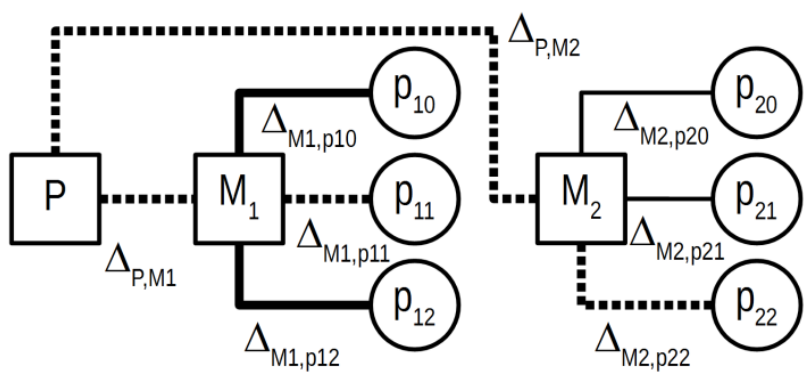

Fig. 6: Compact graph of a mobile machine $M$ on a part $P$.

The locating error of a given plane, in relation the part reference frame, is obtained by the sum of these defects (cf Tab. 2). For a batch of $n$ planes machined for a given position of the machine, the flatness of the planes group (CZ) is given by their identical defects of machine setting and deflection. For $n$ planes machined with $k$ machine positions, the repositioning defect (which is identical, in the worst case) should be added to obtain the flatness of the planes CZ.

Tab. 2: Simulation of part quality with mobile machine.

\begin{tabular}{cl}
\hline $\begin{array}{c}\text { 1 plane/part } \\
\text { locating }\end{array}$ & $\Delta \mathrm{P}, \mathrm{p}_{10}=\Delta \mathrm{P}, \mathrm{M}_{1}+\Delta \mathrm{M}_{1}, \mathrm{p}_{10}+\mathrm{FD}$ \\
\hline $\boldsymbol{n}$ planes, 1 pos. & $\Delta \mathrm{p}_{10}, \mathrm{p}_{12}=\Delta \mathrm{M}_{1}, \mathrm{p}_{10} / 2+\Delta \mathrm{M}_{1}, \mathrm{p}_{12} / 2+$ \\
flatness & $\mathrm{FD}=\Delta \mathrm{M}_{\mathrm{i}}, \mathrm{p}_{\mathrm{j}}+\mathrm{FD}$ \\
\hline $\boldsymbol{n}$ planes, $\boldsymbol{k}$ pos. & $\Delta \mathrm{p}_{11}, \mathrm{p}_{22}=\Delta \mathrm{P}, \mathrm{M}_{1} / 2+\Delta \mathrm{P}, \mathrm{M}_{2} / 2+$ \\
flatness & $\Delta \mathrm{M}_{1}, \mathrm{p}_{11} / 2+\Delta \mathrm{M}_{2}, \mathrm{p}_{22} / 2+\mathrm{FD}=$ \\
& $\Delta \mathrm{P}, \mathrm{M}_{\mathrm{i}}+\Delta \mathrm{M}_{\mathrm{i}}, \mathrm{p}_{\mathrm{j}}+\mathrm{FD}$ \\
\hline
\end{tabular}

The form deviations of the mobile machines have been identified experimentally with the cutting test campaign (Pt). In order to simulate the manufacturable precision for 
the machined part, let us estimate some values for the missing data. It can be assumed that the technics implemented for the repositioning of both machine on the part enables a similar precision $\Delta \mathrm{P}, \mathrm{M}_{\mathrm{i}} \leq \pm 0.5 \mathrm{~mm}$, e.g., and a repeatability of the machine setting of $\Delta \mathrm{M}_{\mathrm{i}}, \mathrm{p}_{\mathrm{j}} \leq \pm 0.2$ $\mathrm{mm}$, e.g.

In this way, the geometric tolerances can be associated with these simulations of machined workpiece precision, as a function of the form deviations measured for each mobile machine. The simulation results are given in Table 3.

The proposed model enables the estimation of the manufacturable tolerances. Better results are obtained with the portable milling machine, with a flatness of $1.8 \mathrm{~mm}$. It shows that a particular attention should be paid the repositioning of the machine.

Tab. 3: Simulation of the manufacturable geometric tolerances.

\begin{tabular}{|c|c|c|c|c|c|c|}
\hline Tolerance $[\mathrm{mm}]$ & \multicolumn{3}{|c|}{ Machine FD $=0.4$} & \multicolumn{3}{|c|}{ Robot $F D=0.8$} \\
\hline $\begin{array}{l}1 \text { plane/part } \\
\text { locating }\end{array}$ & $\theta$ & 1,8 & $\mathrm{P}$ & $\theta$ & 2,4 & $P$ \\
\hline $\begin{array}{l}n \text { planes, } 1 \text { pos. } \\
\text { flatness }\end{array}$ & $\square$ & 0,8 & $C Z$ & $\square$ & 1,2 & \\
\hline $\begin{array}{l}n \text { planes, } k \text { pos. } \\
\text { flatness }\end{array}$ & $\square$ & 1,8 & $C Z$ & $\square$ & & $C Z$ \\
\hline
\end{tabular}

\section{CONCLUSION}

During this feasibility study, about one hundred cutting tests were carried out with two mobile machines, which were envisaged for the machining of large dimension parts. Acceptable operating conditions were found for face milling of steel part with a poly-articulated robot. Nevertheless, the restrictions are too important, due to their lack of rigidity. The second machine envisaged, the portable milling machine, is therefore recommended, even if its repositioning is an issue.

The intrinsic precision of the two mobile machines was quantified experimentally by geometric measurements of the machined surfaces. A modeling has been proposed to estimate the manufacturable precision, given the intrinsic and repositioning defects of the mobile machines.

A perspective of the present study would be the investigation of the repositioning and setting defects.

\section{ACKNOMLEDGEMENT}

The authors acknowledge the funding by the French government, through the UBA3M project of the Institute of Research and Technology IRT Jules Verne.

\section{REFERENCES}

[Uriarte 2013] Uriarte, L., Zatarain, M., Axinte, D., YagüeFabra, J., Ihlenfeldt, S., Eguia, J., Olarra, A. Machine tools for large parts, CIRP Annals, 2013, Vol. 62, No. 2, pp. 731-50.

[Abdi 2009] Abdi, M. R. Fuzzy multi-criteria decision model for evaluating reconfigurable machines, International Journal of Production Economics, 2009, Vol. 117, No. 1, pp. 1-15.
[Verl 2019] Verl, A., Valente, A., Melkote, S., Brecher, C., Ozturk, E., Tunc, L. Robots in machining, CIRP Annals, 2019, Vol. 68, No. 2, pp. 799-822.

[Ji 2019] Ji, W., Wang, L. Industrial robotic machining: a review, The International Journal of Advanced Manufacturing, 2019, online, pp. 1-17

[Chanal 2006] Chanal, H., Duc, E., Ray, P. A study of the impact of machine tool structure on machining processes, International Journal of Machine Tools and Manufacture, 2006, Vol. 46, No. 2, pp. 98-106.

[Dumas 2011] Dumas, C., Boudelier, A., Caro, S., Garnier, S., Ritou, M., Furet, B. Development of a robotic cell for trimming of composite parts, Mechanics \& Industry, 2011, Vol. 12, No. 6, pp. 487-494.

[Brunete 2018] Brunete, A., Gambao, E., Koskinen, J., Heikkilä, T., Kaldestad, K. B., Tyapin, I., Hovland, G. et al., Hard material small-batch industrial machining robot, Robotics and Computer-Integrated Manufacturing, 2018, Vol. 54, pp. 85-99.

[Cordes 2017] Cordes, M., Hintze, W. Offline simulation of path deviation due to joint, compliance and hysteresis for robot machining, International Journal of Advanced Manufacturing Technology, 2017, Vol. 90, pp. 1075-1083.

[Bondarenko 2012] Bondarenko, D., Pashkevich, A., Briot, S., Ritou, M., Furet, B. Elasto-dynamic model of robotic milling process considering interaction between tool and workpiece, Proceedings of the ASME 11th Biennial Conference on Engineering Systems Design and Analysis, Nantes, France, 2-4 July 2012. ESDA2012-82239, Vol.3, pp. 217-226.

[Mousavi 2017] Mousavi, S., Gagnol, V., Bouzgarrou, B. C., Ray, P. Dynamic Modeling and Stability Prediction in Robotic Machining, International Journal of Advanced Manufacturing Technology, 2017, Vol. 88, pp. 3053-3065.

[Cordes 2019] Cordes, M., Hintze, W., Altintas, A. Chatter stability in robotic milling, Robotics and Computer Integrated Manufacturing, Vol. 55, 2019, pp. 11-18.

[Pan 2006] Pan, Z., Zhang, H., Zhu, Z., Wang, J. Chatter analysis of robotic machining process, Journal of Material Processing Technologies, Vol. 173, 2006, pp. 301-309.

[Abele 2010] Abele, E., Altintas, Y., Brecher, C. Machine tool spindle units, CIRP Annals - Manufacturing Technology, Vol. 59, 2010, pp. 781-802.

[Rabreau 2017] Rabreau, C., Noel, D., Le Loch, S., Ritou, M., Furet, B. Phenomenological model of preloaded spindle behavior at high speed, International Journal of Advanced Manufacturing Technology, Vol. $90 n^{\circ} 9-12, p$. 3643-3654, 2017.

[Klimchik 2017] Klimchik, A., Ambiehl, A., Garnier, S., Furet, B., Pashkevich, A. Comparison Study of Industrial Robots for High-Speed Machining. In: Mechatronics and Robotics Engineering for Advanced and Intelligent Manufacturing. Lecture Notes in Mechanical Engineering, 2017, pp. 135-149.

[Legoff 2004] Legoff, O., Tichadou, S., Hascoët J.-Y. Manufacturing Errors Modelling: Two Three-Dimensional Approaches. Proceedings of the Institution of Mechanical Engineers, Part B: Journal of Engineering Manufacture, 2004, Vol. 218, No. 12, pp. 1869-1873.

[Tichadou 2013] Tichadou, S., Legoff, O. Geometric Manufacturing Simulation. In Geometric Tolerancing of Products, pp. 275-304. John Wiley \& Sons, Ltd, 2013. 